\title{
Performance of a hydrostatic sampler for collecting samples at the water-sediment interface in lakes
}

\author{
Lucas P. GONZALEZ, Pedro TEMPORETTI ${ }^{1) *}$ and Fernando PEDROZO ${ }^{1)}$ \\ Water Quality and Aquatic Resources Studies Group, Centro Regional Universitario Bariloche, Universidad Nacional del Comahue, \\ Unidad Postal: Universidad, (8400) Bariloche, Argentina \\ ${ }^{1)}$ Researchers of CONICET \\ * e-mail corresponding author: ptempore@crub.uncoma.edu.ar
}

\begin{abstract}
The water-sediment interface plays a significant role in the determination of the trophic degree of a waterbody. Numerous redox reactions take place there, resulting in the release of contaminants from the sediments to the water column. The aim of the present work was to develop an equipment for collecting samples from the water-sediment interface. Such equipment was to have a simple design, low construction cost, no depth limitations, and high levels of personal safety and to be reliable in the collection of samples. The performance of the hydrostatic sampler thus developed was tested against samples collected either remotely with a corer or directly with syringes by autonomous divers. The hydrostatic sampler permits access to depths where the costs of the traditional diving methodology are expensive, and where working conditions are dangerous for the diver. The hydrostatic sampler provides an additional means of collecting samples from the water-sediment interface, which together with pore-water samples, facilitates the investigation and understanding of chemical mechanisms in lakes, for instance, those that control the P release from sediment to the water column.
\end{abstract}

Key words: Methods, water-sediments interface, lake

\section{INTRODUCTION}

According to Burton \& Repitt (2001), the water-sediment interface is the transition zone between surface water and groundwater. It is an important zone for many reasons: a) it provides essential habitat and refuge for micro-, meio-, and macrofauna or flora; b) it affects the contaminant attenuation, removal and transport; and c) it affects the nutrients and carbon cycles. This zone is characterized by a marked increase in diffusive-transport rates compared to the overlying water (HamiltonTaylor \& Davison 1995). Exchanges across the interface are regulated by different mechanisms associated with the mineral-water balance, such as sorption processes, and redox interactions, which are dependent on oxygen supply and the activities of organisms (Mortimer 1971). The water-sediment interface is a barrier for the free exchange of nutrients and other elements between the sediments and the water column (Horne \& Goldman 1994). At the sediment surface itself, there is generally an oxidized microzone. If the dissolved oxygen is depleted, however, the microzone breaks and several kinds of ions may be released into the water column (Boström 1982). In this respect, the estimation of nutrients coming from the water-sediment interface (internal load) is especially important to the determination of the fluxes of solutes and contaminants within the waterbody (Boström et al. 1988).

The collection of intact samples at the water-sediment interface requires the use of sampling devices, the design of which necessarily includes important features that ensure minimal disturbance of the water-sediment interface and sediment structures, minimal water-flow through the sediment, and a sufficient sample volume (Brinkman et al. 1982).

Methods for the extraction of samples from the water-sediment interface are scarce. One of these methods involves the use of a coring device. Water is extracted from the corer tube by syphoning or with the use of a syringe. Extraction of pore water and water-sediment interface from the sediment corer is still the most widely-used sampling technique, especially in deep water (Jahanke 1988). A large water volume $(20 \mathrm{~mL}$ or greater) (Burton \& Repitt 2001) can be collected with a corer tube. The main problems in sampling arise from: a) the disturbance of sediment by entry of the corer and the affect of resuspended material on the quality of the interface sample; b) the disturbance caused to the samples when the corer is closed; and c) the disturbance caused by the rotation of the corer during the retrieval, resulting in agitation of the sample, re-suspension and redistribution of the sediment within the corer (Blomqvist 1991).

Another common method requires scuba divers to deploy interface and pore-water sampling devices. Adams (1994) described how, in shallow water areas, scuba divers collect the pore water (the water contained between sediment particles) by direct insertion of syringe needles into the sediments. In spite of the fact that this method potentially eliminates the errors which 
can possibly occur with the use of corer devices, the technique is practicably restricted to water depths readily accessible by scuba divers (Adams 1994).

Other methods widely used to collect samples from pore water and from the water-sediment interface include the use of "in situ" dialysis bags and "peepers" (Mayer 1976). These methods can serve as simpler and cheaper alternatives. The principle of operation of the dialysis bags is the equilibration of a contained quantity of water with surrounding water through a dialysis membrane (Hesslein 1976). The dialysis bags can be used equally well for sampling interface water and/or sediment pore water. The peepers are small chambers with a membrane or mesh wall, which are buried in sediments, the surrounding pore water then equilibrating within the chambers. Both dialysis bags and "peepers" are unlikely to alter the chemistry of the sample (Burton $\&$ Repitt 2001). However, several potential sources of error in the dialysis-bag methodology have been reported: the type of membrane, the material for construction of the sampling device, the chemical state of the initial, degassed filling water, the general design of the device, the choice of equilibration time (usually 6 to 15 days: Carignan 1984) and the small volume $(2-5 \mathrm{~mL})$ collected (Burton \& Repitt 2001). However, the dialysis bags are particularly well suited to the study of shallow sediments easily accessible by scuba divers (Carignan 1984). Similar problems associated with these methods were reported by Adams (1994), Ehlke et al. (2004), and Brennwald et al. (2003). In all cases, the importance of simulating as closely as possible the in situ conditions is emphasised (Adams 1994).

Brinkman et al. (1982) developed a shallow water sampler in which the pore water is collected in a tube, either by hydrostatic pressure or vacuum system, after passing through a filter. The device is only useful in waters less than $10 \mathrm{~m}$ deep because the frame with probes has to be pushed into the sediment with a metallic bar.

The aim of our work was to develop equipment for the collection of samples of the water-sediment interface, having a simple design and low construction cost, no substantial depth limitations in its use, high levels of personal safety and performing reliably in the collection of authentic samples. Our study sought to compare its performance with methods involving scuba diving and coring methodologies.

\section{METHODS}

\subsection{Design}

In the design of the hydrostatic sampler (HS) (Fig.1), special attention was given to four aspects: a) the main frame; b) the collecting receptacle; c) the shutting system; and d) the suction system.

The main frame (Fig. 1, 9) was constructed in aluminium with a pyramidal shape, having a base covering $1 \mathrm{~m} 2$ and a height of $0.70 \mathrm{~m}$. The structure is dismountable and the design is modular.

The collecting receptacle (Fig. 1,7) is located at the top of the pyramid and fixed by three screws. This

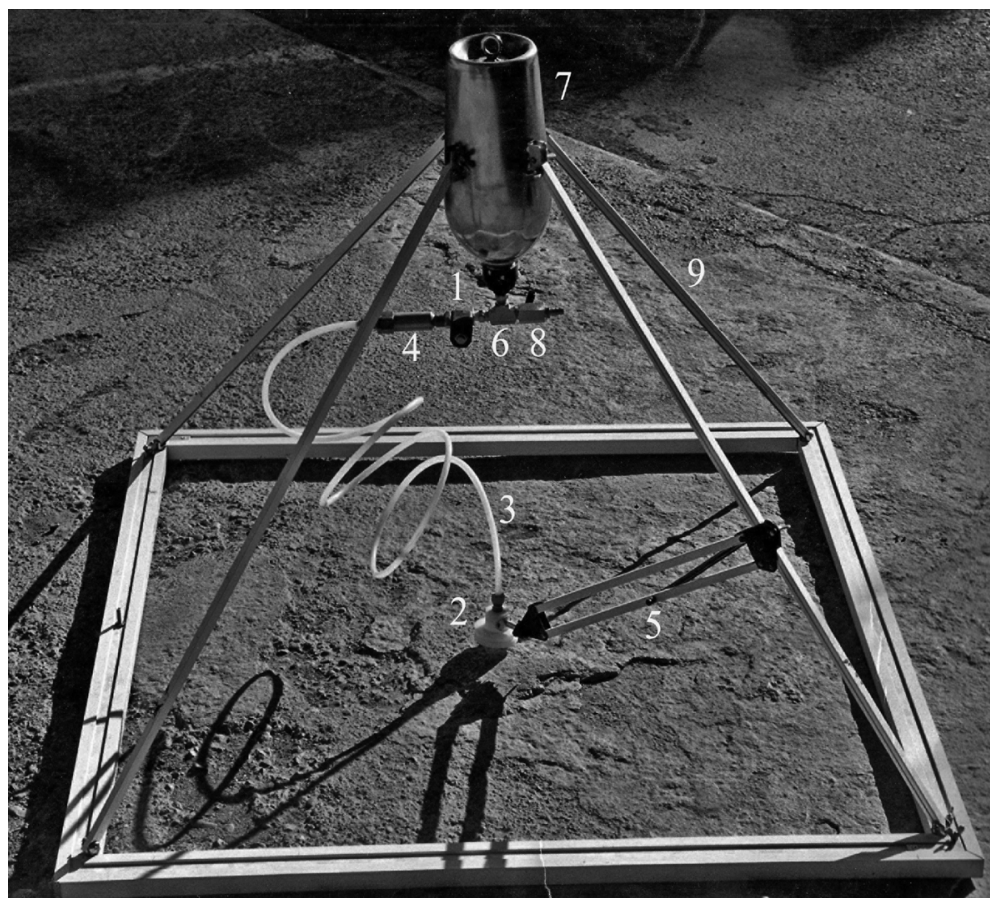

Fig. 1. General view of hydrostatic sampler. 1: Electrovalve; 2: Suctionner; 3: Tube of high pressure; 4: Retention valve; 5: Pantograph arm; 6: Conector tube; 7: Collecting Recipient; 8: Spherical valve; 9: Main frame. 
receptacle is constructed in stainless steel ( $3 \mathrm{~mm}$ thick), is cylindrical in shape with a screwed cover, and has a capacity of 2 litres. The working pressure that this receptacle can bear is $20 \mathrm{~kg} \mathrm{~cm}^{-2}$, with a test pressure of $25 \mathrm{~kg} \mathrm{~cm}^{-2}$.

The suction system (Fig. 1,2) is constructed in a polyamide disk, $10 \mathrm{~cm}$ in diameter and $4 \mathrm{~cm}$ in height, connected to the retention valve by a polypropylene high-pressure tube, $2 \mathrm{~mm}$ in diameter (Fig. 1, 3). The disk is grooved (Fig. 2 A) at its periphery, with 12 radial orifices, each $1 \mathrm{~mm}$ in diameter (Fig. $2 \mathrm{~B}$ ). This design ensures that the collection of the water sample is made in a radial laminar shape. The grooves penetrate up to a central orifice which is connected with the valve system through the high pressure tube.

The suctionner is mobile and was mounted on a pantograph arm (Fig. 1, 5) with two adjustable springs, which prevent the suctionner from burying into the sediment. The suctionner remains parallel to the bottom and less than $10 \mathrm{~cm}$ from it. The panthograph arms permit the suctionner to adapt to the contours of the bottom. The overall weight of the equipment is $5.0 \mathrm{~kg}$; assembly in the field takes approximately 10 minutes.

\subsection{Operation}

The shutting system is operated through three valves (Fig. 1): one electrovalve (1), one retention valve (4), and one spherical valve (8). The electrovalve is activated from the surface by a battery $(12 \mathrm{~V})$. The water gets into the collecting receptacle by means of pressure difference. This difference results from the surface pressure (at $1 \mathrm{~atm}$ ) and the depth pressure (collecting receptacle $=1 \mathrm{~atm}$; external $=1 \mathrm{~atm}+$ hydrostatic pressure); the purpose of the retention valve is to prevent the influx of the water contained in the collecting receptacle during the lifting of the equipment to the surface. The spherical valve controls the flux of the sample manually from the collecting recptacle to the storage and/or transport vessel. The pressure accumulated when the electrovalve is opened at the selected depth draws the sample (collecting receptacle $=1 \mathrm{~atm}+$ hydrostatic pressure; exterior $=1 \mathrm{~atm})$. The apparatus takes a reasonablysized sample (100 to $2000 \mathrm{~mL}$ ); it functions within a range of depths, from 5-100 m.

\subsection{Additional Equipment}

In order to increase the utility of the device, it is possible to add probes for measuring $\mathrm{pH}$, conductivity, dissolved oxygen and redox potential, and for measuring timed intervals through the use of a dataloger.

\subsection{Performance}

The performance of HS was compared with the samples obtained by two other methods, using either a corer
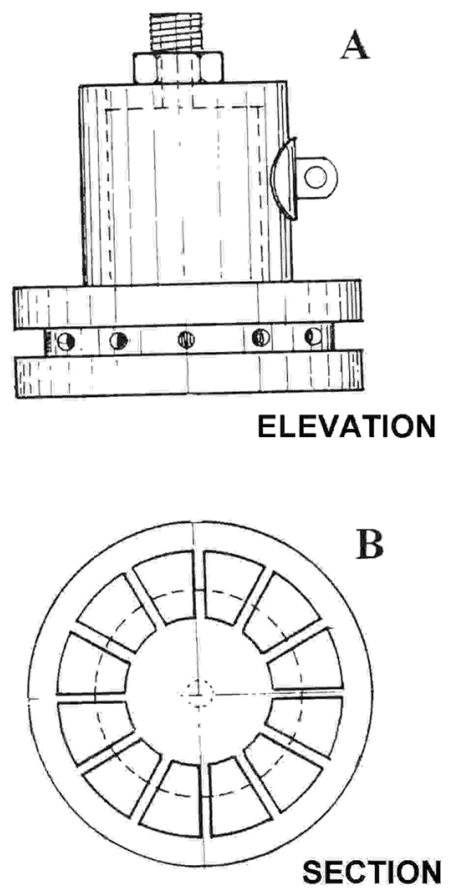

Fig. 2. Suction system detail. Elevation (A) and Section (B).

(CORER) or by scuba diving (SYRINGE). The latter device was arbitrarily taken as the reference method, considering that the diver does not touch the sediment with the syringe and accurately controls the place from where the sample is obtained. Re-suspension was minimal or avoided altogether. In order to select the most favourable location for comparative sampling using the three methods, the bottom was first surveyed by using an echo sounder. Two Patagonian lakes $\left(41^{\circ} 30\right.$ 'S; $71^{\circ} 30^{\prime} \mathrm{W}$ ) were selected for the performance comparisons: a) Moreno Lake (a contaminated site), where a fish-farming facility is installed in a protected bay (samples were collected directly under the breeding cages); and b) the oligotrophic, unpolluted Gutierrez Lake. The physical and chemical characteristics of both lakes have been published in Pedrozo et al. (1993). At the contaminated site (Moreno), the sediment was very soft, characterized by a high accumulation of organic matter and high nutrient concentrations. In contrast, the sediment at the uncontaminated site (Gutierrez) was dominated by sand, with low nutrient concentrations and organic-matter content.

Samples from the water-sediment interface in Gutierrez and Moreno lakes were taken on the same day. A homogeneous area $\left(30 \mathrm{~m}^{2}\right)$ with a plain bottom was selected in each lake. All the samples were obtained at a depth of $20 \mathrm{~m}$ and six replicates from the same place 
were obtained with each sampler. The sequence of sampler use progressed from the one least likely to disturb the sediment to the one most likely to do so: SYRINGE, HS and CORER. Each device was used in an undisturbed sector of the sampling area.

Two divers collected the SYRINGE samples. The safety diver remained far above the sediment, while the other descended slowly towards the bottom, collecting the sample after a few minutes to allow resettlement of any material disturbed; after placing the syringe (between 2 and $3 \mathrm{~cm}$ from the sediment, approximately), the sample was collected.

The HS was submerged slowly, checking the "landing" with an echo sounder; this allowed the descending speed to be reduced in the last meters and to avoid resuspending sediment on impact. Once the apparatus was rested on the sediment, a further 10 to 15 minutes were allowed for any disturbed particles to re-settle. After that, the electrovalve was activated and water flowed to the collecting receptacle. The electrovalve was then closed and the rising of the HS commenced.

To collect the CORER sample, we used a Kajak-type gravimetric sampler (Blomqvist 1991), equipped with acrylic tubes of $3 \mathrm{~cm}$ of diameter and an upper retrocession-proof valve. The gravimetric sampler falls by gravity from the water surface, and the speed of the fall is controlled to avoid excessive penetration into the sediment and to minimisedisturbance of the sample. Upon returning to the surface, water was siphoned from the acrylic tube, and the $5 \mathrm{~cm}$ layer adjacent to the sediment surface was separately sub-sampled and retained.

The $\mathrm{pH}$, the conductivity and the redox potential (Eh) of each sample were measured on collection, using specific electrodes and corrected to a standardized temperature. The samples were stored in pre-cleaned polyethylene flasks and kept in a cold and dark environment; they were then transported immediately to the laboratory (taking no more than 3 hours). In the laboratory, one fraction of each sample was filtered through $0.45 \mu \mathrm{m}$ membrane filters, prior to analytical determination of reactive soluble phosphorus (SRP), nitrates $\left(\mathrm{N}^{-} \mathrm{NO}_{3}{ }^{-}\right.$), nitrites $\left(\mathrm{N}^{-\mathrm{NO}_{2}}{ }^{-}\right)$, and ammonium $\left(\mathrm{N}^{-\mathrm{NH}_{4}}{ }^{+}\right)$. The total fractions of phosphorus (TP) and nitrogen (TN) were determined by the sample without filtering. In all cases, the methodology followed APHA (1992) recommendations. All analyses were performed by triplicate.

In order to test the performance of HS, the results were analysed using the Kruskal-Wallis rank sum test. The different nutrient concentrations in the three samplers were not normally distributed. The Kruskal-Wallis test is a nonparametric alternative to a one-way analysis of variance (ANOVA) and does not assume sample normality (Conover 1980; McCullagh \& Nelder 1989). In all cases in which statistically significant differences were observed, a Multiple Comparison Procedure (Dunnett's and Tukey test) was followed in order to distinguish sampler performances.

\section{RESULTS}

Table 1 shows the chemical composition of watersediment interface taken by three samplers in both sites.

a) Uncontaminated site (Gutierrez Lake):

The samples collected at this site using HS showed departures in the average detected values of TP $(34 \mu \mathrm{g}$ $\left.\mathrm{L}^{-1}\right), \mathrm{TN}\left(145 \mu \mathrm{g} \mathrm{L}^{-1}\right), \mathrm{N}^{-\mathrm{NO}_{3}}-\left(4 \mu \mathrm{g} \mathrm{L}^{-1}\right)$ and $\mathrm{N}^{-\mathrm{NH}_{4}}{ }^{+}(7$ $\mu \mathrm{g} \mathrm{L^{-1 }}$ ) from those in the samples obtained by SYRINGE (TP $=12 \mu \mathrm{g} \mathrm{L}^{-1}, \mathrm{TN} 64 \mu \mathrm{g} \mathrm{L}^{-1}, \mathrm{~N}^{-N^{-}}{ }_{3}^{-}=1 \mu \mathrm{g}$ $\mathrm{L}^{-1}$, and $\left.\mathrm{N}^{-\mathrm{NH}_{4}^{+}}=5 \mu \mathrm{g} \mathrm{L}^{-1}\right)$.

Comparing the results obtained from samples collected by HS and SYRINGE in the uncontaminated site, the samples collected by SYRINGE show that the nutri-

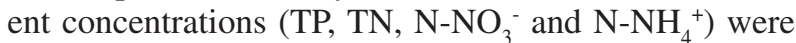
between 1.2 and 3.4 times lower than samples collected by HS. These results are more overwhelming when analysing the nutrient concentration variation range (Tab. 1) for both methods.

The statistical analysis performed in the uncontami-

Tab. 1. Chemical composition of interface water collected by three samplers (average and standard deviation, in brakett).

\begin{tabular}{|c|c|c|c|c|c|c|c|c|c|}
\hline & $\mathrm{pH}$ & $\begin{array}{l}\text { Conductivity } \\
\left(\mu \mathrm{S} \mathrm{cm}^{-1}\right)\end{array}$ & $\begin{array}{l}\text { Redox } \\
(\mathrm{mV})\end{array}$ & $\begin{array}{c}\mathrm{TP} \\
\left(\mu \mathrm{g} \mathrm{L}^{-1}\right)\end{array}$ & $\begin{array}{c}\mathrm{TN} \\
\left(\mu \mathrm{g} \mathrm{L}^{-1}\right)\end{array}$ & $\begin{array}{c}\text { SRP } \\
\left(\mu \mathrm{g} \mathrm{L}^{-1}\right)\end{array}$ & $\begin{array}{l}\mathrm{N}-\mathrm{NO}_{3}^{-} \\
\left(\mu \mathrm{g} \mathrm{L}^{-1}\right)\end{array}$ & $\begin{array}{l}\mathrm{N}-\mathrm{NO}_{2}^{-} \\
\left(\mu \mathrm{g} \mathrm{L}^{-1}\right)\end{array}$ & $\begin{array}{l}\mathrm{N}-\mathrm{NH}_{4}^{+} \\
\left(\mu \mathrm{g} \mathrm{L}^{-1}\right)\end{array}$ \\
\hline \multicolumn{10}{|c|}{ Uncontamined site } \\
\hline SYRINGE & $6.8( \pm 0.1)$ & $63.1( \pm 1.7)$ & $215.0( \pm 4.4)$ & $12( \pm 2)$ & $64( \pm 10)$ & $2( \pm 1)$ & $1( \pm 0.5)$ & $1( \pm 0.1)$ & $5( \pm 4)$ \\
\hline HS & $6.7( \pm 0.1)$ & $62.5( \pm 0.5)$ & $222.0( \pm 5.8)$ & $34( \pm 19)$ & $145( \pm 85)$ & $2( \pm 1)$ & $4( \pm 2)$ & $1( \pm 0.5)$ & $7( \pm 1)$ \\
\hline CORER & $6.7( \pm 0.1)$ & $63.1( \pm 1.7)$ & $220.0( \pm 6.5)$ & $73( \pm 52)$ & $208( \pm 68)$ & $3( \pm 1)$ & $3( \pm 0.4)$ & $1( \pm 0.4)$ & $14( \pm 14)$ \\
\hline \multicolumn{10}{|c|}{ Contamined site } \\
\hline SYRINGE & $6.6( \pm 0.0)$ & $38.2( \pm 1.3)$ & $247.5( \pm 35.1)$ & $70( \pm 34)$ & $53( \pm 15)$ & $10( \pm 2)$ & $4( \pm 1)$ & $0.4( \pm 0.1)$ & $4( \pm 2)$ \\
\hline HS & $6.6( \pm 0.1)$ & $36.5( \pm 0.6)$ & $211.0( \pm 4.7)$ & $16( \pm 3)$ & $48( \pm 5)$ & $6( \pm 1)$ & $2( \pm 1)$ & $0.4( \pm 0.2)$ & $5( \pm 2)$ \\
\hline CORER & $6.7( \pm 0.0)$ & $40.6( \pm 2.6)$ & $251.0( \pm 14.6)$ & $2414( \pm 1859)$ & $319( \pm 215)$ & $104( \pm 76)$ & $4( \pm 0.4)$ & $1( \pm 0.6)$ & $154( \pm 215)$ \\
\hline
\end{tabular}


nated site (Gutierrez Lake) did not show significant differences $(p<0.05)$ for any of the parameters analysed with the three samplers. In that sense, we would deduce that the three devices give comparable results. Considering all the analyses made, SYRINGE (reference method) was the device with the least variability. However, the main limitation for using this sampler is the scuba diving depth.

b) Contaminated site (Moreno Lake):

At this site, these results were opposite to those obtained in the uncontaminated lake, with higher values of these parameters being registered in the samples obtained with SYRINGE (TP $\left(70 \mu \mathrm{g} \mathrm{L}^{-1}\right), \mathrm{TN}\left(53 \mu \mathrm{g} \mathrm{L}^{-1}\right)$, SRP $\left(10 \mu \mathrm{g} \mathrm{L}^{-1}\right)$ and N-NO${ }^{-}\left(3 \mu \mathrm{g} \mathrm{L}^{-1}\right)$ than those collected by HS (TP $\left(16 \mu \mathrm{g} \mathrm{L}^{-1}\right)$, TN $\left(48 \mu \mathrm{g} \mathrm{L}^{-1}\right)$, SRP $(6 \mu \mathrm{g}$ $\left.\mathrm{L}^{-1}\right)$ and $\mathrm{N}^{-N^{-}}{ }_{3}^{-}\left(2 \mu \mathrm{g} \mathrm{L}^{-1}\right)$ (Tab. 1).

The nutrient concentration from samples collected by HS were 1.1 and 4.4 times lower than the samples

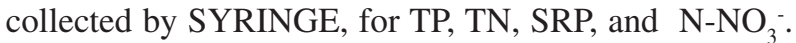
For samples collected by HS, the nutrient concentration variation ranges were lower than the ones collected by SYRINGE.

We did not observe significant differences $(p>0.05)$ between SYRINGE and HS for all parameters analysed except those of redox potential and $\mathrm{N}^{-\mathrm{NO}_{3}}{ }^{-}(\mathrm{n}=6 ; p$ $<0.05$ ). The HS would appear to perform similarly to the reference method. However, the statistical analysis between HS and CORER showed significant differences $(\mathrm{n}=6 ; p<0.05)$ for conductivity, redox potential, TP, $\mathrm{SRP}, \mathrm{TN}$, and $\mathrm{N}^{-\mathrm{NO}_{3}}{ }^{-}$. A greater variability for the majority of parameters analysed between either sampler was observed (Tab. 1). On the other hand, we observed significant differences $(\mathrm{n}=6 ; \quad p<0.05)$ between SYRINGE and CORER for $\mathrm{pH}, \mathrm{TP}, \mathrm{RSP}$ and TN. This showed that CORER was, at this site, the least effective of the three samplers.

\section{DISCUSSION}

Disturbance of bottom sediments is a consequence of the force of impact that a sediment-sampling device makes when it reaches the sediment or rests on it. A high-performance sampler for water sediment interface should make little impact on the sediment surface, thus minimising disturbance, resuspension of particles and release of nutrients dissolved in the sediment interstitial water nutrients. Blomqvist (1985) showed that, when a device with narrow-mouthed coring tubes was used, the surface sediment was easily resuspended during the sampling, thus producing a disturbance in the water flow through the tube during descent, sediment penetration, and ascent. Our results suggest that the CORER produces a high disturbance because of the sudden penetration in the sediment which resuspends particles, thus altering the balance conditions breaking the interface and releasing nutrients from the sediment to the water column.
Although the HS produced more disturbance in the samples collected in the contaminated site compared to the SYRINGE, it was still low compared to that produced by the CORER (as the HS only stands on the sediment). At the contaminated site, the HS showed better efficiency than SYRINGE; this might be due to disturbances produced by the diver while collecting the sample with the latter method. In the contaminated sediments, the slightest disturbance produces an immediate alteration in the balance conditions in the water-sediment interface. In this respect, HS produces minimal disturbances when its large base rests on the bed. However, special care should be given to avoid its sinking into soft sediment.

On the other hand, the HS allows work to be undertaken at depths where the costs of the traditional diving methodology are expensive, and where working conditions are dangerous for the diver.

The water-sediment interface samples collected by HS provide an additional tool together with pore water samples to understand the chemical mechanisms that control the Prelease from sediment to the water column.

\section{AKNOWLEDGMENTS}

The authors wish to acknowledge Dr. Kurt Friese and Dr. Colin Reynolds for reviewing the manuscript and commenting on it; Dr. Nora Baccalá and Lic. Guadalupe Beamud, for her collaborations in Statistic analysis; Tec. Acuic. Walter López and Lic. Gustavo Baffico for their collaboration in the different tests performed on the equipment; Ms. Adriana Diaz for her collaboration with figures. This work was financed by the European Union, contract N ${ }^{\circ}$ TS3-CT93-0203.

\section{REFERENCES}

Adams, D.D. 1994. Sediment Pore Water Sampling,. In: A. Mudroch and S. Macknigth (Eds), Handbook of Techniques for Aquatic Sediments Sampling. Lewis Publishers, Boca Ratón: 171-202.

APHA. 1992. Standard Methods for the Examination of Water. 18th. Ed. American Public Health Association, Washington: $1175 \mathrm{pp}$.

Blomqvist, S. 1991. Quantitative Sampling of Soft-bottom Sediments: Problems and Solutions. Mar. Ecol. Prog. Ser., 72: 295-304.

Boström, B.1982. Recycling of Nutrients from Lake Sediments. Acta Universitatis Upsaliensis, Uppsala, Sweden $\mathrm{N}^{\circ}$ $659.25 \mathrm{pp}$.

Boström, B., J. M. Andersen, S. Fleischer \& M. Jansson. 1988. Exchange of phosphorus across the sediment-water interface. Hydrobiologia, 170: 229-244.

Brennwald, M.S., M. Hofer, F. Peeters, W. Aeschbach-Herting; K. Strassmann, R. Kipfer \& D.M. Imboden. 2003. Analysis of Dissolved Noble Gases in Porewater of Lacustrine Sediments. Limnol. Oceanogr. Methods, 1: 51-62.

Brinkman, A.G., W. Van Raaphorst \& L. Lijklema. 1982. In situ Sampling of Interstitial Water from Lake Sediments. Hydrobiologia 92: 659.

Burton, G. A. \& A. Repitt. 2001. Stormwater Effects Handbook: A Toolbox for Watershed Managers Scientists 
and Engineers. Environmental Protection Agency (EPA). Lewis Publisher: 992 pp.

Carignan, R.1984. Intersticial Water Sampling by Dialysis: Methodological Notes. Limnol. Oceanogr., 29: 667-670.

Conover, W. G. 1980. Practical Nonparametrics Statistics. 2 Edition. Texas Tech University. John Wiley \& Sons, Inc. Toronto, Canada: 493 pp.

Ehlke, T.A., T.E. Imbrigiotta \& J.M. Dale. 2004. Laboratory comparison of polyethylene and dialysis membrane diffusion samplers. Ground Water Monitoring and Remediation. 24(1): 53-59.

Hamilton-Taylor, J. \& W. Davison. 1995. Redox-Driven Cycling of Trace Elements in Lakes. In Physics and Chemistry of Lakes. Lerman, Imboden and Gat (Ed.). Springer: $334 \mathrm{pp}$.

Hensslein, R.H. 1976. An in-situ sampler for close interval pore water studies. Limnol. Oceanogr., 21: 912-914.
Horne, A. J. \& CH. R. Goldman. 1994. Limnology. 2nd Edition. McGraw-Hill, Inc.: 576 pp.

Jahnke, R. A. 1988. A simple, Realiable, and Inexpensive PoreWater Sampler. Limnol. Oceanogr., 33(3): 483-487.

Mayer, L. M. 1976. Chemical Water Sampling in Lakes and Sediments with Dialysis Bags. Limnol. Oceanogr., 21: 912-914.

McCullagh, P. \& J. A. Nelder. 1989. Generalized Linear Models. New York: Chapman and Hall: 325 pp.

Mortimer, C.H. 1971. Chemical Exchanges between Sediments and Water in the Great Lakes-Speculations on Probable Regulatory Mechanisms. Limnol. Oceanogr., 16(2): 387-404.

Pedrozo, F., S. Chillrud, P. Temporetti, \& M. Diaz. 1993. Chemical Composition and Nutrient Limitation in Rivers and Lakes of Northern Patagonian Andes $\left(39.5^{\circ}-42^{\circ} \mathrm{S} ; 71\right.$ ${ }^{\circ}$ W) (Rep. Argentina). Verh. Internat. Verein. Limnol., 25: 207-214.

Received: November 2007

Accepted: February 2008 